\title{
Mortality in young people admitted to hospital for diabetes: database study
}

Stephen E Roberts, Michael J Goldacre, H Andrew W Neil

See also p 750

People with type 1 diabetes mellitus have an increased risk of death at a young age. We aimed to quantify this risk in a population of people admitted to hospital for type 1 diabetes and to determine whether mortality in the three year period after admission has fallen in recent years.

\section{Methods and results}

From 1968 to 1996, for people aged under 30 years in the area covered by the Oxford record linkage study (population of 0.9 million in 1968, 1.9 million in 1974, and 2.5 million in 1987) we analysed all NHS hospital admissions for diabetes mellitus (ICD-9, code 250) in which that condition was coded as the principal diagnosis. The database included linkage to death certificate data to 1999.

The coding of type 1 diabetes is uncommon on hospital records. We chose age 29 as our upper age limit because almost all people under 30 admitted with diabetes mellitus would have had type 1 diabetes. We analysed multiple admissions for the same person as follows. Each person's first admission was identified and followed for three years. At the end of a person's three year follow up, any subsequent admission was included for a "new" period of three year follow up. Standardised mortality ratios were calculated for the study population.

There were 4992 admissions (2603 (52.1\%) male) for diabetes among people aged under 30 years. There were 58 deaths during the three year follow up period (standardised mortality ratio $8.5 ; 95 \%$ confidence interval 6.5 to 10.8 ; table), including 32 in the first year (14.1; 9.6 to 19.4) and 15 during the first hospital admission. Standardised mortality ratios were 27.9 (14.8 to 45.2) at one year and 12.9 (7.6 to 19.5) at three years for the 1010 patients who had been recorded at admission as having diabetic ketoacidosis or coma.

The underlying cause of death or coroners' verdicts were diabetes mellitus (29 cases), other diseases (14), suicide (9) and accidents (6). Three year standardised mortality ratios were 818 (547 to 1143) for diabetes mellitus, 12.6 (9.1 to 16.6) for all natural causes, 11.7 (5.3 to 20.6) for suicide, and 2.2 (0.4 to 5.5) for accidents. Sex specific standardised mortality ratios for suicide were 5.0 (0.9 to 12.3 ) in men and 35.2 (12.7 to 69.1 ) in women (table). All cause death rates per 1000 admissions declined a little, but not significantly, over the study period; standardised mortality ratios were largely unchanged.

\section{Comment}

Young people admitted to hospital for diabetes have an increased risk of death in the following three years, not only from natural causes but also from suicide. Although, in absolute terms, death in young people with diabetes is uncommon, standardised mortality ratios showed that death within three years of hospital
Number of hospital admissions for diabetes in people aged <30 years, 1968-1996, with number of deaths, mortality per 1000 admissions, and standardised mortality ratios during three year follow up period. Values in parentheses are $95 \%$ confidence intervals

\begin{tabular}{|c|c|c|c|}
\hline & \multicolumn{3}{|c|}{ Three year follow up } \\
\hline & $\begin{array}{l}\text { No of } \\
\text { deaths }\end{array}$ & $\begin{array}{c}\text { Mortality per } \\
1000 \text { admissions }\end{array}$ & $\begin{array}{c}\text { Standardised } \\
\text { mortality ratio* }\end{array}$ \\
\hline \multicolumn{4}{|c|}{ Males and females combined $(n=4992 \dagger)$ : } \\
\hline All deaths & 58 & $11.6(8.8$ to 15.0$)$ & $8.5(6.5$ to 10.8$)$ \\
\hline All natural causes*: & 43 & $8.6(6.2$ to 11.6$)$ & $12.6(9.1$ to 16.6$)$ \\
\hline Diabetes & 29 & $5.8(3.9$ to 8.3$)$ & 818.1 (547 to 1143$)$ \\
\hline All illnesses excluding diabetes & 14 & $2.8(1.5$ to 4.7$)$ & $4.1(2.3$ to 6.6$)$ \\
\hline All non-natural causes*: & 15 & $3.0(1.7$ to 5.0$)$ & $4.4(2.5$ to 6.9$)$ \\
\hline Accidents & 6 & $1.2(0.4$ to 2.6$)$ & $2.2(0.4$ to 5.5$)$ \\
\hline Suicides & 9 & $1.8(0.8$ to 3.4$)$ & $11.7(5.3$ to 20.6$)$ \\
\hline \multicolumn{4}{|l|}{ Age (years)‡: } \\
\hline $0-12(n=1636)$ & 10 & $6.1(2.9$ to 11.2$)$ & 5.5 (2.6 to 9.5$)$ \\
\hline $13-19(n=1461)$ & 13 & $8.9(4.7$ to 15.2$)$ & $7.4(3.9$ to 12.0$)$ \\
\hline $20-29(n=1895)$ & 35 & 18.5 (12.9 to 25.6$)$ & $10.8(7.5$ to 14.6$)$ \\
\hline \multicolumn{4}{|l|}{ Period admitted‡: } \\
\hline $1968-78(n=1398)$ & 16 & 11.4 (6.6 to 18.5$)$ & $7.3(4.2$ to 11.3$)$ \\
\hline $1979-88(n=2104)$ & 28 & 133 (8.9 to 19.2$)$ & $9.3(6.2$ to 13.1$)$ \\
\hline $1989-96(n=1490)$ & 14 & $9.4(5.1$ to 15.7$)$ & $8.2(4.4$ to 13.0$)$ \\
\hline \multicolumn{4}{|c|}{ Cause of death by admission period (all natural causes): } \\
\hline $1968-78$ & 14 & $10.0(5.5$ to 16.7$)$ & $11.9(6.5$ to 18.9$)$ \\
\hline $1979-88$ & 19 & $9.0(5.4$ to 14.1$)$ & $13.2(7.9$ to 19.8$)$ \\
\hline $1989-96$ & 10 & 6.7 (3.2 to 12.3$)$ & $11.8(5.6$ to 20.2$)$ \\
\hline \multicolumn{4}{|c|}{ Cause of death by admission period (all non-natural causes): } \\
\hline $1968-78$ & 2 & $1.4(0.2$ to 5.2$)$ & $2.0(0.2$ to 5.6$)$ \\
\hline $1979-88$ & 9 & $4.3(2.0$ to 8.1$)$ & $5.8(2.6$ to 10.2$)$ \\
\hline $1989-96$ & 4 & $2.7(0.7$ to 6.9$)$ & $4.6(1.2$ to 10.2$)$ \\
\hline
\end{tabular}

\section{Males and females separately*:}

All deaths:

\begin{tabular}{lccc} 
All deaths: & 30 & $11.5(7.8$ to 16.4$)$ & $6.5(4.4$ to 9.0$)$ \\
\hline Male & 28 & $11.7(7.8$ to 16.9$)$ & $12.8(8.5$ to 17.9$)$ \\
\hline Female & & & \\
\hline All suicides & 3 & $1.2(0.2$ to 3.4$)$ & $5.0(0.9$ to 12.3$)$ \\
\hline Male & 6 & $2.5(0.9$ to 5.5$)$ & $35.2(12.7$ to 69.1$)$ \\
\hline Female &
\end{tabular}

${ }^{*}$ See bmj.com for detailed notes about multiple admissions, calculations of the standardised mortality ratios, assignment of cause of death, and sex specific standardised mortality ratios.

†Number of hospital admissions. Of the total 4992 admissions, 2603 were in males, 2385 were in females, and in four the sex was not recorded.

¥Standardising mortality (per 1000 admissions) for age and sex made little difference to these results.

admission was nine times more common than in the general population. These ratios were higher than those of 2 to 4 recently reported from population based diabetes cohorts and registers. ${ }^{1-3}$ This suggests that people with type 1 diabetes who need hospital admission are at much greater risk of mortality, at least in the short term after care, than the population of people with type 1 diabetes as a whole. Increased risk of suicide has previously been reported in men with diabetes, ${ }^{3}{ }^{4}$ but we found an even higher risk in young women.

Other studies have reported improvements in prognosis in recent decades for people with type 1 diabetes. ${ }^{15}$ We found no appreciable improvement, however, in young people admitted to hospital for

Unit of Health-Care Epidemiology, Department of Public Health, University of Oxford, Oxford OX3 7LF

Stephen E Roberts epidemiologist Michael J Goldacre professor of public health

continued over

BMJ 2004;328:741-2 Further details about the study's methods and results are at + bmj.com 
Department of Public Health, University of Oxford

H Andrew W Neil reader in clinical epidemiology

Correspondence to: S E Roberts stephen.roberts@ uhce.ox.ac.uk diabetes in the past 30 years. Because methods for glycaemic control and the delivery of insulin therapy have improved over time, the proportion of people admitted with diabetes whose condition is difficult to control is unlikely to have increased. Survival of young people with type 1 diabetes whose disease was serious enough to warrant admission is therefore not likely to have improved much.

Leicester Gill, Glenys Bettley, and Myfanwy Griffith built the database. We thank Myfanwy Griffith and David Yeates for programming.

Contributors: SER and MJG designed the study and wrote the first draft of the manuscript; SER analysed the data; and HAWN contributed to study design, interpretation, and further drafts. SER and MJG are guarantors for the paper.

Funding: The Oxford record linkage study was a project of the former Oxford Regional Health Authority. The Unit of HealthCare Epidemiology is funded by the Department of Health to analyse the linked data.
Competing interests: None declared.

Ethical approval: The historical data files were built with approval from the Oxford Region Data Protection Steering Group and the Health Authorities' Caldicott Guardians; and are wholly anonymised. Ethical approval was not needed for analysis of anonymised statistical datasets.

1 McNally PG, Raymond NT, Burden ML, Burton PR, Botha JL, Swift PG, et al. Trends in mortality of childhood-onset insulin-dependent diabetes mellitus in Leicestershire: 1940-1991. Diabet Med 1995;12:961-6.

2 Laing SP, Swerdlow AJ, Slater SD, Botha JL, Burden AC, Waugh NR, et al The British Diabetic Association cohort study, I: all-cause mortality in patients with insulin-treated diabetes mellitus. Diabet Med 1999;16:459-65. patients with insulin-treated diabetes mellitus. Diabet Med 1999;16:459-65.
Wibell L, Nystrom L, Ostman J, Arnqvist H, Blohme G, Lithner F, et al. Wibell L, Nystrom L, Ostman J, Arnqvist H, Blohme G, Lithner F, et al.
Increased mortality in diabetes during the first 10 years of the disease. A population-based study (DISS) in Swedish adults 15-34 years old at diagnosis. J Intern Med 2001;249:263-70.

Kyvik KO, Stenager EN, Green A, Svendsen A. Suicides in men with IDDM. Diabetes Care 1994;17:210-2.

Nishimura R, Matsushima M, Tajima N, Agata T, Shimizu H, LaPorte RE. A major improvement in the prognosis of individuals with IDDM in the past 30 years in Japan. The Diabetes Epidemiology Re past 30 years in Japan. The Diabetes Epidemiology Research (Accepted 27 November 2003)

\section{Does the type of competing interest statement affect readers' perceptions of the credibility of research? Randomised trial}

Sara Schroter, Julie Morris, Samena Chaudhry, Richard Smith, Helen BarrattTopic: 344;215;166

BMJ Editorial

Office, BMA House

Tavistock Square,

London WC1H 9JR

Sara Schroter

senior researcher

Richard Smith

editor

Helen Barratt

research assistant

Medical Statistics

Department,

Education and

Research Centre,

Wythenshawe

Hospital,

Manchester

M23 9LT

Julie Morris

head of medical

statistics

General Surgery,

North Staffordshire

University Hospital,

Stoke-on-Trent

ST4 7LN

Samena Chaudhry

preregistration house

officer

Correspondence to:

S Schroter

sschroter@bmj.com

BMJ 2004;328:742-3
Financial relationships among industry and academic institutions are diverse and common. ${ }^{1}$ These interests can influence authors' conclusions ${ }^{2}$ and readers' perceptions of published studies. ${ }^{3}$ We report the effects on reader perceptions of different statements of competing interests for two manuscripts.

\section{Participants, methods, and results}

We used computer generated random numbers from the British Medical Association's membership database (to select $900 B M J$ readers). We randomised 450 to be sent a paper about the use of problem lists in letters between hospital doctors and general practitioners ${ }^{4}$ (problem lists paper) and 450 to be sent a paper indicating that the impact of pain from herpes zoster on patients' daily functioning may be substantial (herpes paper). ${ }^{5}$ We previously reported a study using the herpes paper, ${ }^{3}$ and we have incorporated the results from that study in this paper. For each of the papers, 150 readers received the paper with no competing interests declared, 150 with a financial statement, and 150 with a statement that the author was a recipient of funding for studentships and research grants.

The competing interest statements for each group were as follows. For both papers, when the type of competing interest was "none," the phrasing of the statement was "none declared."

For the herpes paper, when the type of competing interest was "financial," the statement read "The authors are employees of Tohen Research Laboratories, Tohen and Co, Inc, Connecticut, and potentially own stock and/or hold stock options in the company. When the type of competing interest was "grant," the statement read "KH is a recipient of funding for studentships and research grants from Tohen Laboratories Limited."

For the problem lists paper, when the type of competing interest was "financial," the statement read: "AT is an employee of Tohen Laboratories Limited, makers of medical management software and potentially owns stock or holds stock options within the company." When the type of competing interest was "grant," the statement read: "AT is a recipient of funding for studentships and research grants from Tohen Laboratories Limited, makers of medical management software."

Readers scored the studies in terms of interest, importance, relevance, validity, and believability on 5 point scales (for example, $1=$ extremely uninteresting to $5=$ extremely interesting). We estimated that 91 readers were needed in each group to achieve a power of $90 \%$ to detect a meaningful difference in scores between the groups of approximately 0.5 units (characterised by a variance of means of $0.047-$ for example, means of 3.3,3.4, and 3.8), by using a one way analysis of variance with the conventional 5\% significance level and assuming a common standard deviation of 1.0. We used an analysis of variance model to evaluate the impact of type of competing interest (none declared, financial, grants) on ratings of interest, importance, relevance, validity, and believability and to assess the influence of type of paper (herpes, problem

Full details of the results for each paper and the interaction + effects are on bmj.com

This article was posted on bmi.com on 23 February 2004: http://bmj.com/cgi/doi/10.1136/bmj.38035.705185.F6 